\title{
Türkiye’de Mevcut İlk ve Orta Öğretim Programlarının Jeomiras ve Jeopark Bilincinin Oluşmasına Etkileri
}

\author{
Effects of the Present Primary and High School Education Programmes \\ In Turkey On the Formation of Consciousness for Geoheritage and Geoparks \\ With a View to Protecting Them
}

\author{
Emine GÜNOK \\ Gazi Üniversitesi, Gazi Eğitim Fakültesi, Coğrafya Eğitimi Anabilim \\ Dal,,06500Ankara (eminegunok@me.com)
}

\section{ÖZ}

Jeolojik korumanın ana unsurları olan Jeomiras ve Jeopark, üzerinde yaşadıkları fiziki çevreyi kişi ve toplumlara anlatabilmenin yöntemi veya uygulamaları olarak ele alınabilir. Çevreyi doğru tanımamanın en yaygın sonucu doğal afetlerdir. Öte yandan, artan nüfus ile onun doğurduğu hızlı yapılaşma ve çeşitlenen hammadde tüketimi doğanın hızlı tahribatına, dolayısıyla yerkürenin geçmişi için belge niteliğinde olan jeolojik ögelerin ortadan kalkmasına yol açmaktadır. Jeolojik miras olan bu varlıkların yok olması ise yerkürenin anlaşılmasını güçleştirmektedir. Jeopark ve jeolojik miras, ergin bireylerin uğraşlarıdır, kısmen eğitim içerir. Gelişmiş toplumlarda ise doğa koruma bilinci, okul öncesinden başlayarak ilk ve orta öğretimde verilir, kalıcı ve gerçekçi olanı budur. Bu konuda başlı başına dersler olduğu gibi, Fen Bilgisi, Çevre, Yaşam, Biyoloji, Coğrafya vb derslerin kapsamları amaca uygun olarak zenginleştirilmiştir. Ülkemizdeki durumun tespiti için ilköğretim ve ortaöğretim dersleri ve ders kapsamları incelenmiştir. Sonuç ümit verici olmaktan uzaktır. Müfredatta Jeolojik Koruma, Jeopark, Jeolojik Miras kavramları kelime olarak bile yoktur.

Anahtar Kelimeler: İlk ve Orta Öğretim, Jeolojik Miras, Jeopark.

\section{ABSTRACT}

As the core elements of geologic protection; Geological Heritage and Geoparks can be considered as the practical ways for expressibility of the physical environment to people and community, on which they have been spending their life. The natural disasters are the most widespread consequence of unknown environment. On the other hand, structuring as the consequence of fast increasing population and the diversifying raw material consumption cause destruction of the nature and give rise to disappearance of Geological Heritage which are reference legibility's for the past of the Earth. The disappearance of these 
wealth makes the understanding of the Earth extremely difficult. Dealing with geoparks and geological heritage involve partial education which has to be the adult people occupation. The awareness for protection of the nature is practiced in the developed countries by commencing prior to school education and taught in primary and high school levels, which is realistic and perdurable. The syllabus of lessons such as science, environment, life, biology, geography etc. are enriched in accordance with the objective and there are also specific lessons on these topics. In order to identify the status of our country with this respect, the lessons and their syllabus of primary and secondary schools are investigated. The conclusions are far-off from being hopeful where the concepts of "geologic protection", "geopark" and "Geological Heritage" do not exist even as vocabulary in the syllabus.

Keywords: Geological Heritage, Geoparks, Primary and High School Education

\section{GİRIŞ}

Çevre koruma bilincinin temelini yerkürenin korunması oluşturur. Bunun için halkın, Yerküre hakkında bilgilendirilmesi ve bilinçlendirilmesi gereklidir. Bu ise ilköğretimden itibaren okullarda ve medya aracılığıly yeterli düzeyde yerbilimleri eğitimi ile mümkündür.

Ülkemizde, çevre eğitimi, biyolojik ve kimyasal koruma konularında oldukça yeterli düzeyde verilmektedir. Ancak çevre korumanın temelini oluşturan yerkürenin korunması konusunda aynı hassasiyetin gösterildiği söylenemez.

Yerkürenin korunması için yerküre ile ilgili jeolojik, jeomorfolojik ve coğrafi bilgilerin çocukluktan itibaren öğretilmesi ve tanıtılması gerekir. Ancak böylece tam bir çevre koruma bilinci oluşturulabilir.

\section{JEOPARK VE JEOLOJIKK MİRAS KAVRAMLARININ TANIMLARI, KAPSAMLARI VE İLKELERI}

Konu ile ilgili başlıca kavramlar aşağıda açıklanmıştır:
Jeolojik miras (jeomiras): Yok olmas durumunda bulunduğu bölgeye ait bilgi ve jeolojik bir belgenin kaybolacağı, nadir bulunan, yok olma tehdidi altındaki jeosittir (Wimbledon,1996; Kazanc1, 2010).

Jeosit: Yer kabuğunun oluşumu veya evrimi sırasındaki bir olayı, bir süreci veya bir oluşumu ortaya koyan kayaç-mineral-fosil topluluğu, istif, yer şekli, jeolojik yapı, doku türünden, bilimsel belge niteliği, bazı durumlarda görsel güzelliği bulunan doğal varlıklardır (Wimbledon, 1996; ProGeo Group, 1998; www. progeo.se).

Jeopark: Aynı veya farklı türden jeositlerin topluca bulunduğu alanlardır. Jeopark, doğa koruma ve sürdürülebilir kalkınmanın araçlarından biridir. Jeoparklar içerdikleri jeolojik oluşumlar, biyolojik ve arkeolojik unsurlarla birlikte değerlendirilen doğal alanlardır (Özgen Erdem, 2015). Jeoturizm olgusuyla yerel kalkınmayı destekleyerek iç göçü önler. Yöresel kalkınmayı sağlar. Yeterli düzeyde jeolojik miras objesi ve jeositi barındırır. Her jeoparkın bir ' 'ana teması" vardır. Buna örnek olarak volkanizma, tektonizma verilebilir. Jeopark kendi bünyesindeki 
veya bağlantılı olduğu araştırma birimlerinde yeni bilgilerin üretildiği yerlerdir. Milli Park veya Tabiat Parkı gibi yasal çerçevesi çizilmiş yeni bir koruma biçimi değildir. Bölgesinde var olan bütün yasal sinirlamalara uyar. Yerel halkta jeopark bilinci ve ortaklığg oluşturarak iç barışı destekler.

Jeolojik koruma başlangıçta tamamen bilimsel amaçla, jeolojik araştırmalar için gelecek nesillere aktarılması zorunlu jeolojik yapıların korunması amacıyla ortaya çıkmıştır. Sonraları ise jeositle birlikte çevrenin, canlıların, tarihi ve kültürel değerlerin ve tüm insanlığın korunması gibi, geniş kapsamlı bir misyon yüklenmiştir.

\section{JEOLOJIK KORUMA VE JEOPARK KAVRAMLARININ DÜNYADA VE ÜLKEMIZDEKİ TARİHI GELIŞİM SÜRECI}

Görsel ve bilimsel değeri olan doğal oluşumları koruma fikri, Baumann mağarası ve Giant Causeway'deki uygulamalarla üçyüzelli yıl geriye gider (Burek ve Prosser, 2008; Doughty, 2008; Erikstad, 2008). Modern anlamda jeolojik koruma ve jeomiras kavramları 1944 yılında İngiltere'de jeolojik birimlerin tip kesitlerinin korunması ile başlamıştır.

1991'de yerbilimciler, artan çevre tahribatına karşı, isyan niteliğinde, 30 ülkenin ortak imzası ile "Digne Bildirgesi”ni yayınlamıştır. $\mathrm{Bu}$ bildirgeyle ilk kez, yer kürenin inorganik bölümünün de korunmaya ihtiyacı olduğu belirtilmiş “jeolojik sit - jeosit" ve "jeolojik miras" kavramları yüksek sesle dillendirilmiştir.

1995 y1lında kurulan ProGEO'nun (European Association for the Conservation of Geologial Heritage) faaliyetleri bugünkü gelişmelerin asıl kaynağı olmuştur. PROGEO, Jeomiras konusunda, UNESCO tarafindan desteklenen en geniş sivil toplum örgütüdür. 1995 yılında, Uluslararası Jeoloji Bilimleri Birliği (International Union of Geolgical Sciences), UNESCO'nun da desteğini alarak dünya bazında bir envanter listesi derlemeye ve veri tabanı oluşturmaya başlamıştır. Aynı yıllarda dünyada jeopark ve jeoturizm kavramları da gelişme sürecine girmiştir.

1994'te "Girit Fosil Ağaçlar Müzesi" olarak başlayıp 2000'de kendini "jeopark" olarak ilan eden ve "Avrupa Jeopark A ğı" oluşturduğunu duyuran "Lesbos Jeopark1" (kurucusu Dr. N. Zouros), bugün ikisi de saygin kurumlar olan European Geopark Network-EGN (2000) ve UNESCO Global Geopark Network-GGN (2002) oluşmasına önderlik etmiştir (Kazancı vd., 2015). 2001 yılında UNESCO Jeolojik Mirası Koruma İnisiyatifi oluşturulmuştur.

2002 y1lında Dublin Konferansı'nda Dünya Jeolojik Miras Listesi hazırlama kararı alınmıştır.

UNESCO 1999 y1lından itibaren bu alanda aktif olarak yer almaktadır. Bünyesinde Küresel Jeopark Ağ1 (GGN) kurulmuştur. Bu kuruluş gönüllü bir organizasyondur. Son zamanlarda Avrupa Jeopark Ağı veya Global Jeopark Ağ1 yerine UNESCO Jeoparkı kavramı gelişmiştir.

1999 Yılında Jeolojik Mirası Koruma Derneği (JEMİRKO), Türkiye'de var olan jeositleri ortaya çıkarmak, envantere kaydetmek ve tanıtmak için kurulmuştur.

\section{EĞITIMI AÇISINDAN MEVCUT MÜFREDATIN DEĞERLENDİRİLMESİ}

Bu kapsamda öncelikle ilköğretim ve ortaöğretim müfredatı içerisinde 'Jeopark ve Jeolojik Miras' 
kavramlarının var olup olmadığını tespit etmek için Hayat Bilgisi, Fen ve Teknoloji, Sosyal Bilgiler, Fen Bilimleri, Çevre ve Eğitim, Coğrafya dersleri müfredatları incelenmiş ve bazı sonuçlara ulaşılmıştır.

$$
\text { Yapılan araştırmada aradığımız }
$$

kavramlarla ilişkili ilk konuları ilköğretim 6. Sınıfta yer alan Fen ve Teknoloji dersinde görmekteyiz. Bu derste "Yer Kabuğu Nelerden Oluşur?" (MEB, 2006) isimli 8. Ünitede "Taş Küre”yi oluşturan ana maddeler ve bu maddelerin hayatımızdaki yerinin öğretilmesi hedeflenmiştir. Ünite işlenirken, doğal bir laboratuvar ve müze niteliğinde olan ülkemizin olanaklarından faydalanmak amacıyla çevre gezileri düzenlenmesi ve öğrencilerin mümkün olduğunca arazi gözlemlerine yönlendirilmesi gerektiği belirtilmiştir. Bunun için ülkemizin önemli madenleri, barajları, fosil alanları, bunların yanı sıra mağara, traverten ve peri bacaları gibi "doğal antt" olarak nitelendirilebilecek turistik ve tarihî güzelliklerin olanaklar ölçüsünde ziyaret edilmesi önerilmiştir. Ayrıca okullarda, kayaç, mineral, toprak, maden ve fosil örneklerinin sergilenebileceği laboratuvarların oluşturulmasının çok faydalı olacağı ifade edilmiştir.

$\mathrm{Bu}$ üniteden amaçlanan öğrencilerin; doğal anıtların çok uzun bir süreçte oluştuğunu, tüm insanlığa ait değerler olduğunu, yakın ve uzak çevresinden örnekler ile korunarak gelecek nesillere aktarılmasına yönelik bireysel ve iş birliğine dayalı öneriler sunmasıdır.

$\mathrm{Bu}$ ünitede yapılacak etkinlik örnekleri ise; "Öğrenciler yakın çevrelerinde nelerin "doğal anıt" olarak nitelendirildiğini tartışır, şartlar uygunsa gezip-görüp incelerler. Daha sonra gezigözlem sonuçlarını çeşitli şekillerde sunarlar.”
Ayrıca "Öğrenciler, yurdumuzda çok tanınan doğal anıt örneklerini (Pamukkale travertenleri ve Nevşehir'deki peri bacaları vb.) ve bunların nasıl oluştuğunu çeşitli kaynaklardan (ilgili resmî kurum ve kuruluşlar, ansiklopediler, kütüphane, internet, varsa video-CD vb.) araştırır. Araştırma sonuçlarını görsel materyallerle (fotoğraf, afiş, slayt vb.) destekleyerek sunarlar" biçiminde müfredatta düzenlenmiştir. Müfredatın açıklamalar kısmında ise Yer kabuğunun değişiminin devam eden bir süreç olduğu belirtilerek "Doğal anıtlar; yer kabuğunun oluşum sürecinde ortaya çıkan peri bacaları, traverten, mağara, şelâle, göl vb. biçimlerdeki yeryüzü şekilleri ve özel korumaya alınmış ağaçlardır" şeklinde bir tanıma yer verilmiştir.

Ortaöğretim 11. Sinıfta yer alan Coğrafya dersinde "Küresel Ortam Ünitesinde Bölgeler ve Ülkeler" isimli öğrenme alanında Örnek incelemeler yoluyla ülkelerarası etkileşimde turizm faaliyetlerinin rolünü sorgulamak amaçlanmaktadır. Bu konuda yapılacak etkinlik örnekleri "Dünyanın Hızlı Gelişen Endüstrisi: Turizm” (MEB, 2011) başlı̆̆ı altında Dünyanın önemli turistik değerlerinin harita üzerinde belirlenmesi, rol kartlarının hazırlanarak turizm faaliyetleri ile küresel etkileşim, kültür ve ekonomi ilişkisi kurulmasının sağlanması olarak belirtilmiştir. Ayrıca açıklamalar bölümünde "Dünyanın yedi harikası, dünyanın doğal ve kültürel ortak mirası, millî parklar da verilmelidir" ifadesine yer verilerek araştırma konumuz olan Jeopark ve Jeolojik Miras kavramlarını çağrıştıracak kavramlar kullanılmıştır.

Ortaöğretim 12. Sinıfta yer alan Coğrafya dersinde "Çevre ve Toplum" isimli öğrenme alanında 2011 yılında yapılan değişiklikle "D.12.8 Ortak doğal mirasın ekosistemdeki öneminden 
yola çıkarak doğal miraslara yönelik tehditleri sorgular" şekliyle bir kazanım eklenmiştir. $\mathrm{Bu}$ amaçla yapılacak etkinliklere örnek olarak "Hepimizin Sorumluluğu” başlığı altında "Doğal Mirası Koruma Gazetesi çıkarılabilir. Doğal Mirasların Farkında mıyız? Yakın çevredeki doğal miras alanlarına gezi düzenlenir. Fotoğraf ve görüntüler alınarak "Yakın Çevremizdeki Doğal Miras" konulu bir belgesel hazırlanır, okulda sergilenir" şeklinde yapılacak etkinlikler belirtilmiştir.

Ortaöğretim 12. Sınıfta yer alan Coğrafya dersinde "Çevre ve Toplum" isimli öğrenme alanında ayrıca "D.12.9. Çevre bilincine sahip olur" şeklindeki kazanım 2005 müfredatında yer almakta olup etkinlik örnekleri olarak "Geleceğimize Sahip Çıkmak" başlığı altında "Doğal miras alanları ile ilgili belgesel nitelikteki film, slayt vb. izlenebilir. Yaşadığı yerleşim alanına yönelik doğal mirasın korunması ile ilgili üç ayrı proje geliştirilir. Geliştirilen projeler uygulanabilirlik, maliyet ve fayda açısından değerlendirilir" şeklinde etkinlik örnekleri verilmiştir.

\section{SONUÇLAR VE TARTIŞMA}

"Jeopark, Jeolojik Koruma ve Jeolojik Miras" kavramları 12 yıllık zorunlu eğitim olan İlköğretim ve Ortaöğretim müfredatları içerisinde kavram olarak dahi bulunmamaktadır. Ancak bu kavramları çağrıştıran "Doğal Anıt, Doğal ve Kültürel Miras, Milli Parklar" hakkında sadece 6. Sinıf Fen ve Tekonoloji Dersi ile 12. Sinıf Coğrafya dersinde kısaca bilgi verilmiştir. Ayrıca burada dikkat edilmesi gereken bir diğer husus bu konuların dönem sonlarına gelmesidir. Özellikle konumuza daha yakın konuların 12. Sinıfta verildiği düşünülürse ve ülkemizdeki Lisans
Yerleştirme Sınavlarına (LYS) hazırlık çalışmaları dikkate alındığında öğrencilerin bu konulara yeterince dikkat etmeden hatta görmeden mezun oldukları düşünülür ise durumun ciddiyeti daha iyi anlaşılabilir. MEB'nın müfredatlarında benzer olumsuz bir durum ilgili kavramları da kapsayan çevre eğitimi için de geçerlidir (Demir ve Yalçın, 2014).

Gezegenimizin geçmişinin anlaşılması ve geleceğinin kurgulanabilmesi için "Jeoparkların, Jeolojik Korumanın ve Jeolojik Mirasın” önemi göz önüne alındığında bu konuda bazı değişikliklerin yapılmas1 zorunluluk arz etmektedir. Bahis konusu derslerin müfredatları incelendiğinde bu değişikliklerin çok zor olmayacağı görülecektir. Şekil 1'de grafikle ifade edildiği gibi Hayat Bilgisi İlköğretim'de 1.2.3. sinıflarda, Sosyal Bilgiler 4, 5, 6 ve 7. sinıflarda, Fen ve Teknoloji dersi 3, 4, 5, 6,7 ve 8 . sinıflarda verilmektedir.

Jeopark ve Jeolojik Miras kavramlarının öğrencilere kazandıracağı konular aşağıda sıralanmıştır:

İlköğretim Hayat Bilgisi dersi öğretim programında (MEB, 2015);

1. Sinıfta "Doğa ve Çevre" ünitesinde yakın çevrede bulunan bitki ve hayvanlar, doğa olayları, mevsimler ve özellikleri, doğanın ve çevrenin temiz tutulması ile geri dönüşüm konularıyla ilgili bilgi, beceri ve değerleri kazandırmak amaçlanmaktadır.

2. Sinıfta "Doğa ve Çevre" ünitesinde güneş, toprak, hava ve suyun canlılar için önemi, bitki yetiştirme ve ağaç dikmenin önemi, yönler, doğa olayları sonucu oluşan afetler, insanların çevre üzerindeki olumsuz etkileri, çevre kirliliğinin nedenleri ve geri dönüşüm 
gibi konularla ilgili bilgi, beceri ve değerleri kazandırmak amaçlanmaktadır.

3. Sinıfta "Doğa ve Çevre" ünitesinde sınıfın ve okulun krokisini çizme, afetler, milletin ortak mallarının kullanımı, yön bulma, insan ve doğal çevre etkileşimi ile doğayı ve çevreyi koruma gibi konular hakkında bilgi, beceri ve tutum sahibi olmaları amaçlanmaktadır.

İlköğretim Sosyal Bilgiler Dersi öğretim programında (MEB, 2009);

4. Sinıfta "İnsanlar, Yerler ve Çevreler" ünitesinde çevresinde gördüğü doğal ve beşeri unsurları ayırt eder ve doğal afetler karşısında hazırlıklı olur.

5. Sinıfta "Kültür ve Miras" ünitesinde çevresindeki ve ülkemizin çeşitli yerlerindeki doğal varlıklar ile tarihî mekânları, nesneleri ve yapıtları tanır", "İnsanlar, Yerler ve Çevreler" ünitesinde Türkiye'nin kabartma haritası üzerinde, yaşadığı bölgenin yüzey şekillerini genel olarak tanır. Yaşadığı bölgedeki insanların doğal ortamı değiştirme ve ondan yararlanma şekillerine kanıtlar gösterir. Yaşadığı bölgede görülen doğal afetlerin zararlarını artıran insan faaliyetlerini fark eder.

6. Sinıfta "İnsanlar, Yerler ve Çevreler" ünitesinde konum ile ilgili kavramları kullanarak kıtaların, okyanusların ve ülkemizin coğrafi konumunu tanımlar. Anadolu ve Mezopotamya' da yaşamış ilk uygarlıkların yerleşme ve ekonomik faaliyetleri ile sosyal yapıları arasındaki etkileşimi fark eder. "Küresel Bağlantılar" ünitesinde ülkemizindiğerülkelerleolan ekonomikilişkilerini, kaynaklar ve ihtiyaçlar açısından değerlendirir. Ülkemizin diğer ülkelerle doğal afetlerde ve çevre sorunlarında dayanışma ve işbirliği içinde olmasının önemini fark eder. Uluslararası kültür, sanat, fuar ve spor etkinliklerinin toplumlar arası etkileşimdeki rolünü değerlendirir.

İlköğretim Fen ve Teknoloji dersi öğretim programında (MEB, 2006 );

4. Sinıfta "Gezegenimiz Dünya" ünitesinde üzerinde yaşadıkları Dünya'nın şekli ve yapısını, Dünya'nın yapısında bulunan maddeler ve bu maddelerin önemini öğretmek amaçlanmaktadır.

5. Sinıfta "Dünya, Güneş ve Ay" ünitesinde Güneş, Dünya ve Ay’ın şekil ve büyüklüklerini, Dünya'nın hareketlerini, Ay'ın hareketlerini öğretmek amaçlanmaktadır.

7. Sınıfta "Güneş Sistemi ve Ötesi: Uzay Bilmecesi” ünitesinde öğrencilerin; uzayda bulunan gök cisimlerini ve güneş sistemini kavraması, uzay gözlemlerinin yapılmasına olanak sağlayan optik araçları tanıması yanında, geçmişten günümüze kadar yapılan uzay araştırmaları, teknolojinin uzay araştırmalarına katkısı, bunların gök bilimine yansımaları ve uzay teknolojisinin bazı durumlarda bir kirlilik türü olarak nitelendirilen uzay kirliliğine sebep olabileceği hakkında bilgi, beceri, deneyim ve tutum kazanmaları hedeflenmektedir.

8. Sinıfta "Doğal Süreçler" ünitesinde öğrencilerin Dünya'nın oluşumu, doğal bir süreç olan levha hareketleri ve bu hareketlerin sebep olduğu sonuçların yanında hava olaylarının nasıl oluştuğu ve günlük yaşamımızdaki önemi, iklim ile hava olayları/teknoloji ve hava gözlemi arasındaki ilişki hakkında bilgi, beceri, deneyim ve tutum kazanmaları amaçlanmaktadır.

İlköğretim Çevre Eğitimi ders programında (MEB, 2011); doğayı tanımaları ve doğa ile doğada var olan canlılar arasındaki ilişkiyi anlamaları, doğal dengenin korunmasına yönelik 
önlemler almaları, insan faaliyetlerinin doğanın dengesi üzerindeki etkilerini fark etmeleri, doğal dengenin korunması için madde döngülerinin sürekliliğinin sağlanması gerektiğinin farkına varmaları, madde döngülerinin sürekliliğinin yaşam için önemini kavramaları, doğanın korunmasına yönelik sorumluluk almaları, her insanın doğada olumlu veya olumsuz bir iz bıraktığını kavramaları, ekolojik ayak izi hesaplamalarını yaparak bunun doğal kaynak tüketimi ile ilişkisini kurmaları, doğal kaynakların sürdürülebilir ve verimli kullanımının önemini kavramaları, küresel çevre sorunlarını tanımaları, bu sorunların önlenmesine yönelik sorumluluk almaları, sürdürülebilir kalkınma ile sürdürülebilir doğal kaynak kullanımı arasında ilişki kurmaları, amaçlanmaktadır

Sonuç olarak İlköğretimde 5. ve 7 . Sinıfların ilgili derslerindeki müfredatları konumuz ile büyük ölçüde ilişkili konulardır. $\mathrm{Bu}$ nedenle ilköğretimin 1. Sinıfindan itibaren Jeopark (Jeopark kavramı çocukların en çok ilgisini çekecek kavram olacaktır), Jeolojik Koruma ve Jeolojik Miras Kavramları kademe kademe verilebilir.

Ortaöğretimde 9, 10, 11 ve 12. sinıflarda yer alan tek Yer Bilim dersi olan Coğrafya dersi öğretim programları (MEB, 2011) da dikkatle incelendiğinde konumuzla ilişkili pek çok konunun yer aldığı görülebilir. Ancak burada dikkat edilmesi gereken temel husus, çizelge -1 de görüleceği üzere lise türlerine göre Coğrafya dersinin 9. ve 10. Siniflarda zorunlu 11. ve 12. Sınıflarda seçmeli olduğudur. $\mathrm{Bu}$ nedenle tüm öğrencilerin Jeopark, Jeolojik Koruma ve Jeolojik Miras kavramlarını tanımaları için bu konulara 9. ve 10. Sinıf müfredatlarında yer verilmesi zorunluluğudur.
Ülkemizde ilköğretimde zorunlu ders saati toplamı 213, seçmeli dersler ve serbest etkinlikler ders saati toplamı 25, ortaöğretimde zorunlu ders saati toplamı 85, seçmeli ders saati toplamı 51'dir. Yer bilimi grubundan ortaöğretimde yer alan tek ders Coğrafya dersidir. Üstelik yalnızca 9. ve 10. sinifta zorunlu olarak toplam 4 saat, 11. ve 12. sinıflarda seçmeli olarak toplam 8 saat okutulmaktadır. Sadece ders saatlerine bakıldığında dahi yerbilimlerine ayrılan payın ne kadar düşük olduğu açıkça görülmekte olup; bu saptama bir başka çalışmada da (Demir ve Yalçın, 2014) vurgulanmıştır.

Büyük ölçüde derleme ve/veya değerlendirme makalesi olan bu çalışmada aşağıda sıralanan sonuçlara ulaşılmıştır:

İlk ve orta öğretim müfredatında Jeopark, Jeolojik Koruma ve Jeolojik Miras başlığı altında herhangi bir eğitim verilmemektedir. İlköğretimde okutulan Hayat Bilgisi, Fen Bilimleri, Sosyal Bilgiler dersleri ile Ortaöğretimde okutulan Coğrafya Derslerinde konu ile ilgili olabilecek kazanımlar yer almaktadır. Ancak içerik olarak bu kavramlar bulunmamaktadır.

Bir ağacın kendi büyümesinin ve hayatının kayıtlarını tutması gibi, yerkürenin de kendi geçmişinin ve anılarının kaydını jeolojik miras olarak hem yer yüzeyinde hem yerin derinliklerinde tutuğunu, bu kayıtların okunarak yerkürenin hayatının da insan hayatı gibi tek olduğunun çocuklara öğretilmesi sadece jeolojik mirasın değil dünyanın sürekliliği açısından da elzemdir. 12 y1llık zorunlu eğitim süresince yerküreyi konu alan derslerde özellikle ilköğretim çağlarından başlayarak erken yaşlarda verilmeye başlanması yerkürenin korunması açısından en doğru yöntem olacaktır. Hayat Bilgisi dersiyle 
başlatılacak bu süreç Fen Bilimleri Dersi, Sosyal Bilgiler ve Ortaöğretimde yerbilimleriyle ilgili tek ders olan ve tüm liselerde zorunlu olarak 9. ve 10.
Jeolojik Koruma ve Jeolojik Miras kavramlarının ilişkili konularda verilmesi için gereken düzenleme yapilmalidir.

sinıflarda okutulan Coğrafya dersinde Jeopark,

Çizelge 1. Liselerde Coğrafya ders saatlerinin sınıflara göre dağılışı (MEB, 2010).

Table 1. The distribution of Geography teaching hours in high schools according to lessons (MEB, 2010).

\begin{tabular}{|c|c|c|c|c|}
\hline \multirow{2}{*}{ OKULLAR } & \multicolumn{2}{|c|}{ Zorunlu Dersler } & Seçmeli Dersler & \\
\cline { 2 - 5 } & SINIFLAR & & & \\
\cline { 2 - 5 } & 9 & 10 & 11 & 12 \\
\hline Genel Lise & 2 & 2 & 4 & 4 \\
\hline Anadolu Lisesi & 2 & 2 & 4 & 4 \\
\hline Fen Lisesi & 2 & 2 & 4 & 2 \\
\hline Sosyal Bilimler Lisesi & $3(S-2)$ & 2 & & 4 \\
\hline Spor Lisesi & 2 & 2 & 4 & 4 \\
\hline Güzel Sanatlar Lisesi & 2 & 2 & 4 & 4 \\
\hline Anadolu Öğgretmen Lisesi & 2 & 2 & 4 & \\
\hline
\end{tabular}

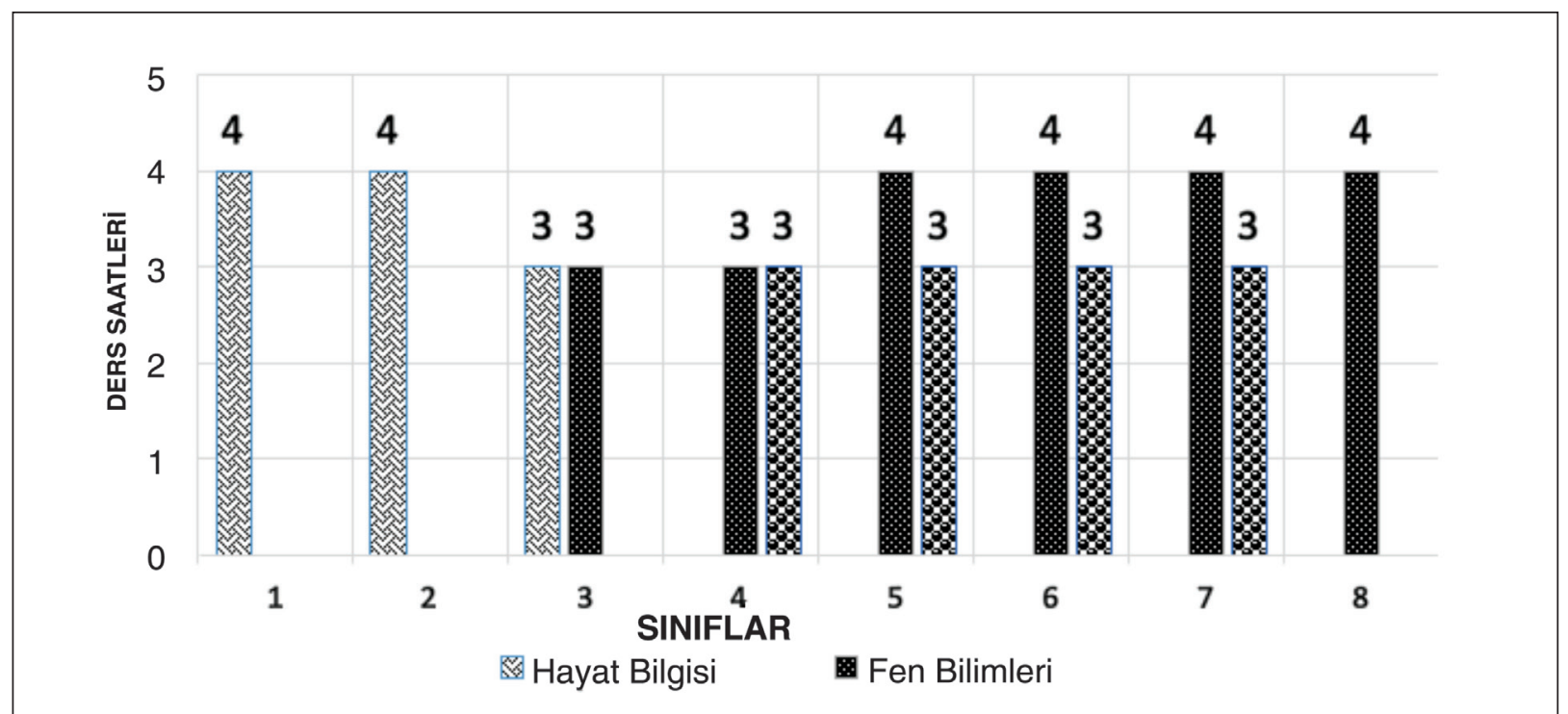

Şekil 1. İlköğretimde Jeopark ve Jeolojik Miras kavramları ile ilişkili derslerin ve ders saatlerinin sınıflara göre dağılışı (MEB, 2010).

Figure 1. The distribution of lessons and their teaching hours related to Geopark and Geological Heritage concepts in primary schools according to lessons (MEB, 2010). 


\section{KATKI BELIRTME}

$\mathrm{Bu}$ yazı Nizamettin Kazancı'nın (A.Ü.) yönlendirmeleri, Yaşar Suludere'nin (Jemirko) destekleriyle hazırlanmıştır. Hocalarıma her türlü katkılarından dolayı müteşekkirim. Ayrıca, bilimsel hakem olarak önerileriyle makalenin son şeklini almasında Hüseyin Yalçın'ın emeği geçmiştir.

\section{EXTENDED SUMMARY}

The concepts, "Geological Heritage" and "Geopark" can be considered as a methodology or an application for explaining the physical environment in which a person or a society lives in. The common result of the unawareness of the natural environment is natural hazards. On the other hand, accelerated population and related increase in occupation and consumption of natural resources lead to destruction of the nature and also the geological heritage which is, by definition, an archive of the Earth's natural history.

\section{Geopark and Geological Heritage} concepts are adult occupation which partly includes education. Advanced societies educate their youth on principles of natural protection at pre-school, primary and high school levels which is both realistic and perdurable. There are specific lessons designed as well as Science, Environment, Biology Geography are enriched on the topic. The awareness for protection of the nature is practiced in the developed countries by commencing prior to school education and taught in primary and high school levels, which is realistic and perdurable. The syllabus of lessons such as science, environment, life, biology, geography etc. are enriched in accordance with the objective and there are also specific lessons on these topics.
At current state, we do not have any lessons in Turkey's present primary and high school syllabus concerning Geopark, Geological Protection, and Geoheritage. The primary school lessons such as social life, physical and social sciences and geography classes in higher education are relevant but do not include these terms. With an analogy explaining the geological heritage as an archive which records earth's history both on surface and underground such as a tree ring which records a tree's living history, it is essential to teach students that earth's life is as sacred as human life. In order to protect the earth, during the 12 year obligatory education should include topics on earth sciences especially starting from the primary school. This process should start with social life classes and continue with physical and social science courses in primary school level and the geography classes which are mandatory in high school level in 9 and 10th grades should be enriched with the terms such as Geopark, Geological Protection and Geoheritage.

\section{DEĞIINILLEN BELGELER}

Burek, C.V., Prosser, C. D. 2008. The History of Geoconservation. Geological Society, Spec. Pub. 300, London, $312 \mathrm{~s}$.

MEB (Milli Eğitim Bakanlığı), (2006). İlköğretim Fen ve Tekonoloji Dersi, (6, 7 ve 8. Sinıflar) Öğretim Programı. Ankara: MEB Yayınevi

MEB, (2009). Sosyal Bilgiler Dersi, 4.-5. Sinıf Programı. Ankara: MEB Yayınevi

MEB, (2009). Sosyal Bilgiler Dersi, 6.-7. Sinif Programı. Ankara: MEB Yayınevi

MEB, (2010). İlköğretim Kurumları Haftalık Ders Çizelgesi. Ankara: MEB Yayınevi 
MEB, M. E. (2010). Ortaöğretim Kurumları Haftalık Ders Çizelgesi. Ankara: MEB Yayınevi

MEB, (2011). Ortaöğretim Coğrafya Dersi (9, 10, 11 ve 12. Sınıflar) Öğretim Programı. Ankara: MEB Yayınevi

MEB, (2011) Ortaokul Çevre Eğitimi Dersi Öğretim Program1. Ankara: MEB Yayınevi

MEB, (2015). İlkokul Hayat Bilgisi Dersi, (1, 2 ve 3. Sınıflar) Öğretim Programı.Ankara: MEB Yayınevi

Doughyt, P. 2008. How things began: the origin of geological conservation. İç: The History of Geoconservation (Ed. C.V. Burek ve C.D. Prosser), Geol. Soc.Spec.Pub. 300, London, s. 7-16

Demir, E., \& Yalçın, H. (2014). Türkiye'de çevre eğitimi. Türk Bilimsel Derlemeler Dergisi, 7(2), 07-18.

Erikstad, L. 2008 History of geoconservation in Europe. İç: The History of Geoconservation (Ed. C.V. Burek ve C.D. Prosser), Geol. Soc.Spec.Pub. 300, London, s. 249-256

Kazanc1, N. 2010. Jeolojik Koruma: Kavramlar ve Terimler, Jeolojik Mirası Koruma Derneği, Ankara, 60 s.
Kazanc1, N., Şaroğlu, F., Suludere, F. 2015. Jeolojik Miras ve Türkiye Jeositleri Çatı Listesi, MTA Dergisi 151:263-272

Özgen Erdem, N.Ö. 2015. Jeoparklar ve Küresel Ağlar ile Bütünleşmenin Önemi, TMMOB Jeoloji Mühendisleri Odas1, Haber Bülteni, 2015/2, Ankara, s.5

ProGeo Group. 1998. A first attempt at a geosites framework for Europe-an IUGS initiative to support recognition of World heritage and Europen geodiversity. Geologica Balcanica 28, 5-32

Wimbledon, W. A. P. 1996 National site election, a stop on the road to a European Geosite List. Geologica Balcanica 26, 15-27

$\begin{array}{ll}\text { Makale Geliş Tarihi } & : \text { 1 Eylül } 2016 \\ \text { Kabul Tarihi } & : \text { 27 Aralık } 2016 \\ & : \text { 1 September } 2016 \\ \text { Received } & : \text { 27 December } 2016\end{array}$

